\title{
Selective catalytic conversion of bio-ethanol to propene: a review of catalysts and reaction pathways
}

Chemical Resources Laboratory, Tokyo Institute of Technology, 4259-R1-5 Nagatsuta, Midori-ku, Yokohama, 226-8503 Japan. E-mail, iwamoto@res.titech.ac.jp

Masakazu Iwamoto

\begin{abstract}
The conversion of ethanol to propene were examined on $\mathrm{Ni}$ ion-loaded silica MCM-41(Ni-M41), Sc-modified $\mathrm{In}_{2} \mathrm{O}_{3}\left(\mathrm{Sc} / \mathrm{In}_{2} \mathrm{O}_{3}\right)$, and a solid solution of $\mathrm{Y}_{2} \mathrm{O}_{3}-\mathrm{CeO}_{2}$. The propene production activity was in the order, $\mathrm{Sc} / \mathrm{In}_{2} \mathrm{O}_{3}>\mathrm{Y}_{2} \mathrm{O}_{3}-\mathrm{CeO}_{2}>\mathrm{Ni}-\mathrm{M} 41$, while their stability during the reaction was $\mathrm{Y}_{2} \mathrm{O}_{3}-\mathrm{CeO}_{2} \sim \mathrm{Sc} / \mathrm{In}_{2} \mathrm{O}_{3}>$ Ni-M41. The propene yield and durability of $\mathrm{Sc} / \mathrm{In}_{2} \mathrm{O}_{3}$ were greatly improved by addition of water and hydrogen in the reactant stream. The reaction mechanism was greatly dependent on the catalyst employed. On Ni-M41, the metathesis reaction of ethene and butenes, produced through dimerization of ethene, was a key step for the propene formation. On the remaining two oxide catalysts, the major pathways were the common: ethanol $\rightarrow$ acetaldehyde $\rightarrow$ acetone $\rightarrow$ propene. The detailed reaction pathways, however, were different from each other. On Sc/ $\operatorname{In}_{2} \mathrm{O}_{3}$, acetaldehyde was oxidized to acetic acid with water or a surface hydroxyl group and the resulting acetic acid was converted to acetone and carbon dioxide through ketonization. On the other hand, on $\mathrm{Y}_{2} \mathrm{O}_{3}-\mathrm{CeO}_{2}$, acetaldehyde was converted to ethyl acetate, and then it decomposed to form acetic acid and ethene. Acetic acid was converted to acetone and carbon dioxide in the same manner as that on $\mathrm{Sc} / \mathrm{In}_{2} \mathrm{O}_{3}$. The by-production of much amounts of ethene was characteristic on $\mathrm{Y}_{2} \mathrm{O}_{3}-\mathrm{CeO}_{2}$. On the $\mathrm{Sc} / \mathrm{In}_{2} \mathrm{O}_{3}$ oxide, a hydrogen molecule


was active for the hydrogenation of acetone to 2-propanol. In contrast, on the $\mathrm{Y}_{2} \mathrm{O}_{3}-\mathrm{CeO}_{2}$ oxide, hydrogenation of acetone did not proceed with hydrogen but did with the co-fed ethanol, that is, by the Meerwein-Ponndorf-Verley reduction.

Key words

Ethanol, Propene, Nickel, Indium Oxide, Cerium Oxide, Scandium, Heterogeneous Catalysis

\section{Introduction}

The use of bioethanol (bEtOH) as an alternative (or additive) for automobile fuels has increased rapidly all over the world. This is one way of using renewable resources to suppress carbon dioxide emissions, while another challenge is the conversion of bEtOH to various olefins and their use for production of chemicals and polymers [1-7]. The latter would be very significant for the long-term fixation of carbon dioxide. Many efforts have therefore been devoted to the development of systems for converting bEtOH to ethene and other lower olefins. In particular conversion to propene is desirable due to the greater demand for propene derivatives, such as propene oxide, acrylonitrile, and polypropene [2].

Catalytic conversions of EtOH on zeolites [3-5] and metal oxides [6, 7] have widely been studied. On zeolites, the activity and selectivity in the many studies reported so far are insufficient. The major weakness is catalyst deactivation. For example, the selectivity towards propene on proton- or metal-modified zeolites is usually ca. $20-30 \%$ and decreases with reaction time, although sometimes higher propene selectivity values are observed upon catalyst degradation [3-5]. Oligomerization, polymerization, and fission reactions on strong acid sites in zeolite pores result in the formation of propene and butenes due to shape selectivity [3-5]. However, the random reactions in the pores finally result in coke 
formation and short catalyst life times. EtOH can also react on metal oxide surfaces to give various chemicals. Acid sites are widely recognized to lead to dehydration of EtOH, giving ethene, while basic sites lead to dehydrogenation to yield acetaldehyde [6, 7]. As a result, many kinds of products, for example aldehydes, ketones, ethene, and butenes, have been observed on oxide catalysts. In this catalysis, butenes and other higher olefins are produced by oligomerization of ethene, but as far as we are aware significant propene production on oxide catalysts has not been reported.

At first, our attention was devoted to nickel ion-loaded mesoporous silica MCM-41 (Ni-M41) because it was active towards the synthesis of propene from ethene, by dimerization of ethene and subsequent metathesis of the resulting butenes with unreacted ethene [8]. Therefore, Ni-M41 is a possible catalyst for the conversion of EtOH to propene since M41 is active for the dehydration of EtOH to yield ethene [8b]. Indeed, this was confirmed by our group [9] and subsequently by Sugiyama et al. [10]. The pore diameters of M41 are usually 1.5-5.0 nm, and, therefore the product distribution on the catalysts is not controlled by shape selectivity. The reaction pathways are of interest.

On the other hand, various metal oxide-based catalysts have been examined as catalysts for the conversion of ethanol, but most of the products besides ethene are oxygenated compounds, such as aldehydes, ketones, and higher alcohols [11, 12]. Our attention was paid to the selective conversion of $C_{x}$-alcohol to $C_{2 x-1}-$ ketone on ceria-based catalysts [11], and assumed that any acetone formed could be hydrogenated and subsequently dehydrated by controlling the acid-base and redox properties of catalysts. Indeed, yttrium-loaded $\mathrm{CeO}_{2}$ $\left(\mathrm{Y}_{2} \mathrm{O}_{3}-\mathrm{CeO}_{2}\right.$ ) was found by us to show the stable catalytic activity for the selective conversion of ethanol to propene [13]. We also found that not only $\mathrm{Y}_{2} \mathrm{O}_{3}-\mathrm{CeO}_{2}$ but also Sc-modified $\mathrm{In}_{2} \mathrm{O}_{3}\left(\mathrm{Sc} / \mathrm{In}_{2} \mathrm{O}_{3}\right)$ [14] offered new types of catalysis for the production of propene without 
shape selectivity, though the catalytic activity of $\operatorname{In}_{2} \mathrm{O}_{3}$ gradually decreased with duration at $30 \mathrm{vol} \%$ of ethanol.

In this review article, we first summarized the catalytic activity of the above three catalysts, Ni-M41, $\mathrm{Y}_{2} \mathrm{O}_{3}-\mathrm{CeO}_{2}$, and $\mathrm{Sc} / \mathrm{In}_{2} \mathrm{O}_{3}$. The effects of the additives for the $\mathrm{In}_{2} \mathrm{O}_{3}$ catalysts were also discussed. Then, it will be shown that the reaction pathways are greatly dependent on the catalysts employed, in which ethene and acetaldehyde worked as respective intermediates on Ni-M41 and on the oxide catalysts.

\section{Catalytic activity of Ni-M41, $\mathrm{Sc} / \mathrm{In}_{2} \mathrm{O}_{3}$, and $\mathrm{Y}_{2} \mathrm{O}_{3}-\mathrm{CeO}_{2}$}

The catalytic activity of these three oxides was studied as a function of the partial pressures of ethanol, water, and hydrogen, the reaction temperature, the reaction time, and the space velocity. The effects of kinds and amounts of metal ions added on the respective catalysts were also investigated. When we examined the catalytic activity, deactivation of the catalysts was observed, which was enhanced under the high partial pressure of ethanol. For example, the propene yield on Ni-M41 was approximately $17 \%$ at $\mathrm{P}_{\text {ethanol }}=5.5 \%$ and did not change in 10-hour experiment [15], while at $\mathrm{P}_{\text {ethanol }}=30 \%$ the conversion degree to propene was $23 \%$ at the initial stage and decreased to $12 \%$ after $10 \mathrm{~h}$. Since the high concentration of ethanol is essential to reduce running costs of the industrial processes, the experimental results indicated difficult employment of Ni-M41 in the practical process.

Typical experimental results on these catalysts are summarized in Table 1 . The experimental conditions were adjusted to respective appropriate ones at which the propene yields were maximized. For example, addition of hydrogen gas into the reactants' gas flow was very effective for the $\mathrm{Sc} / \mathrm{In}_{2} \mathrm{O}_{3}$ catalyst but showed no effect for the $\mathrm{Y}_{2} \mathrm{O}_{3}-\mathrm{CeO}_{2}$ catalyst. This is due to the difference of hydrogenation mechanisms of intermediate acetone on these 
two catalysts, as will be shown in the sections of reaction pathways. The activity order of these three catalysts for the production of propene was $\mathrm{Sc} / \mathrm{In}_{2} \mathrm{O}_{3}>>\mathrm{Y}_{2} \mathrm{O}_{3}-\mathrm{CeO}_{2}>$ Ni-M41. The yield of propene on the $\mathrm{Sc} / \mathrm{In}_{2} \mathrm{O}_{3}$ catalyst reached at $60-65 \%$ which was approximately $80 \%$ of the theoretical maximum, $75 \%$ (as shown later), and sufficiently high in the heterogeneous catalysis. Such high and stable yield of propene has never been reported for zeolites or other catalysts for the conversion of ethanol. The major by-products were iso-butene and carbon dioxide on $\mathrm{Sc} / \mathrm{In}_{2} \mathrm{O}_{3}$, while ethene on the remaining two catalysts. The great distinction among the product distributions clearly resulted from the difference of reaction pathways.

The effects of scandium addition onto the $\mathrm{In}_{2} \mathrm{O}_{3}$ catalyst and of the reaction conditions were introduced here in more detail. The disadvantages of not-modified $\operatorname{In}_{2} \mathrm{O}_{3}$ were deactivation mainly due to the reduction of $\mathrm{In}_{2} \mathrm{O}_{3}$ to In metal and carbon deposition, and low selectivity of propene due to the by-production of acetone. The addition of only $1-3$ atom \% of Sc onto $\mathrm{In}_{2} \mathrm{O}_{3}$ improved the anti-reducibility of $\operatorname{In}_{2} \mathrm{O}_{3}$. We suggested that there would be a certain type of surface defects on $\mathrm{In}_{2} \mathrm{O}_{3}$ which might work as initiation sites of the reduction of oxide during the reaction and that the Sc atoms would be loaded on the sites to prevent the reduction. The similarity of the radius of $\mathrm{Sc}^{3+}$ ion of six-coordination, $0.75 \mathrm{~nm}$, to that of six-coordinated $\mathrm{In}^{3+}$ ion, $0.80 \mathrm{~nm}$, might support the suggestion. The situation and role of Sc added should be clarified in the near future.

The addition effect of water vapor was examined to avoid or reduce deactivation of the catalysts owing to the carbon deposition. The amounts of carbon deposits determined by TG-DTA analysis after the use in reaction decreased to about $1 / 10-1 / 20$ by the water addition. The introduction of water could also improve the yield and stability of propene formation on the $\mathrm{Sc} / \mathrm{In}_{2} \mathrm{O}_{3}$ catalyst. Next, hydrogen addition in the $\mathrm{EtOH}+\mathrm{H}_{2} \mathrm{O}+\mathrm{N}_{2}$ flow 
was examined because one could expect more efficient conversion of acetone to propene. Clearly, the hydrogen addition improved the yield of propene and the stability of the catalyst. In addition, the amount of carbon deposit greatly decreased upon the co-feed of water and hydrogen with EtOH. The appropriate reaction conditions on $\mathrm{Sc} / \mathrm{In}_{2} \mathrm{O}_{3}$ were found to be 8-25 \% water and ca. $30 \%$ hydrogen with $30 \%$ EtOH.

In contrast to $\mathrm{Sc} / \mathrm{In}_{2} \mathrm{O}_{3}$, the active phase of $\mathrm{Y}_{2} \mathrm{O}_{3}-\mathrm{CeO}_{2}$ was the surface solid solution. Upon applying the conventional impregnation method for $\mathrm{Y}_{2} \mathrm{O}_{3}$ on $\mathrm{CeO}_{2}$, the catalytic activity showed the volcano-shaped dependence on the amount of added Y. The appropriate loading amount of Y was approximately 20 atom \%, at which a 1:1 solid solution was produced on the surface. Based on the EXAFS, FT-IR, and TPD results, it was indicated that the densities of oxygen vacancies on the catalysts did not changed with the loading of $\mathrm{Y}_{2} \mathrm{O}_{3}$ but the numbers of strong acid sites decreased at the 20 atom \% Y loading. The maximized catalytic activity would be due to the decreasing ethene yield resulting from the elimination of active acid sites.

The surface structure of Ni-M41 is complicated and still has exactly been undetermined. Various physicochemical techniques were employed to characterize the coordination numbers of oxygen and silicon around a nickel ion loaded on the pore wall of mesoporous silica, their changes with the pore structure and the Si/Ni ratio, and the dependence of the redox behavior of nickel ions on the preparation methods. The findings indicated the formation of a three coordinated $\mathrm{Ni}^{2+}$ ion located on five membered $\mathrm{Si}-\mathrm{O}$ rings. Besides this species, a four coordinated $\mathrm{Ni}^{2+}$ species was found to be formed on six membered Si-O rings. Both species constructed a 2:1 nickel phyllosilicate-like structure after the calcination. The three coordinated species was suggested as an active species for the present reaction and its amount was dependent on the pore diameter and the $\mathrm{Si} / \mathrm{Ni}$ ratio.

The reaction mechanisms including for example the surface structures, the adsorption 
sites, and the states of intermediates have not been resolved yet, and the relation between the structure of catalyst and the reaction pathway has not been clarified. However, the reaction pathways on the respective catalysts were essentially elucidated and will be introduced in the next sections.

\section{Reaction pathways on Ni-MCM-41}

The product distribution was studied as a function of space velocity on Ni-M41 at 673 $\mathrm{K}$. The dependence is summarized in Figure 1. At SV=70,000 $\mathrm{h}^{-1}$ the conversion level of EtOH was ca. $50 \%$, but at 20,000 or below it increased to $95 \%$ or more. The product distribution depends strongly on the space velocity. At higher SVs, 10,000-100,000 $\mathrm{h}^{-1}$, acetaldehyde was produced in large amounts, and the amount decreased monotonically with decreasing SV, which will be discussed later. Diethylether was also produced and its formation showed a behavior similar to that of acetaldehyde, although the amount formed was very small. Ethene was always a major product in the reaction, and its yield reached a maximum at 2,000-3,000 $\mathrm{h}^{-1}$. On the other hand the yields of propene and butenes gradually increased with decreasing SV, indicating that these compounds are products from the terminal phases of consecutive reactions. The formation of diethylether from EtOH and its subsequent decomposition to yield ethene and EtOH was already confirmed on a M41 catalyst [8b] and Ni-M41 catalysts [15]. On the basis of above results, we suggest the following reaction pathways to form propene via diethylether and ethene as intermediates.

$$
\begin{aligned}
& 2 \mathrm{CH}_{3} \mathrm{CH}_{2} \mathrm{OH} \rightarrow \mathrm{CH}_{3} \mathrm{CH}_{2} \mathrm{OCH}_{2} \mathrm{CH}_{3}+\mathrm{H}_{2} \mathrm{O} \\
& \mathrm{CH}_{3} \mathrm{CH}_{2} \mathrm{OCH}_{2} \mathrm{CH}_{3} \rightarrow \mathrm{CH}_{2}=\mathrm{CH}_{2}+\mathrm{CH}_{3} \mathrm{CH}_{2} \mathrm{OH} \\
& 2 \mathrm{CH}_{2}=\mathrm{CH}_{2} \rightarrow \mathrm{CH}_{2}=\mathrm{CHCH}_{2} \mathrm{CH}_{3} \rightarrow \mathrm{CH}_{3} \mathrm{CH}=\mathrm{CHCH}_{3} \\
& \mathrm{CH}_{3} \mathrm{CH}=\mathrm{CHCH}_{3}+\mathrm{CH}_{2}=\mathrm{CH}_{2} \rightarrow 2 \mathrm{CH}_{2}=\mathrm{CHCH}_{3}
\end{aligned}
$$


There is one more important question in the results of Figure 1: the meaning of the increment in acetaldehyde at higher SVs. The results showed that acetaldehyde was an intermediate to form ethene, although the reaction was never suggested. The dehydrogenation of EtOH to acetaldehyde is widely accepted to proceed on various catalysts. No progress in the reverse reaction was first confirmed in the experiment that an equimolar mixture of acetaldehyde and $\mathrm{H}_{2}$ was introduced onto the Ni-M41 catalyst at 573-773 K. Next, an equimolar mixture of EtOH and acetaldehyde was introduced onto the Ni-M41 catalyst at $673 \mathrm{~K}$. Acetaldehyde could be converted into ethene and Equations 3 and 4 subsequently proceeded in this reaction system. In the experiments of Figure 1, a trace amount of ethylacetate was observed, although the amount was not quantified. The following reactions explain the formation of ethene from acetaldehyde.

$$
\begin{aligned}
& 2 \mathrm{CH}_{3} \mathrm{CHO} \rightarrow \mathrm{CH}_{3} \mathrm{COOCH}_{2} \mathrm{CH}_{3} \\
& \mathrm{CH}_{3} \mathrm{COOCH}_{2} \mathrm{CH}_{3} \rightarrow \mathrm{CH}_{3} \mathrm{COOH}+\mathrm{CH}_{2}=\mathrm{CH}_{2} \\
& \mathrm{CH}_{3} \mathrm{COOH}+\mathrm{H}_{2} \rightarrow \mathrm{CH}_{3} \mathrm{CHO}+\mathrm{H}_{2} \mathrm{O}
\end{aligned}
$$

Equation 5 is well-known as the Tishchenko reaction, while Equation 6 is not popular. The reverse reaction of Equation 6, however, was already confirmed to catalytically proceed and was put to practical use by Showa Denko K. K., Japan [16]. To postulate Equation 6 is therefore legitimate. Equation 7 is for the recycle of produced acetic acid using a byproduct hydrogen. The sequence of reactions 5-6-7 would result in the formation of ethene from acetaldehyde through ethylacetate and acetic acid as the intermediates.

In conclusion, two kinds of reaction pathways for the formation of ethene from EtOH on Ni-M41 are revealed, and proceed in parallel. One is the dehydration route, via diethylether as intermediate. The other is a complicated route through acetaldehyde and ethylacetate as intermediates. The reaction rate of the latter route is slower than that of the 
former, since the formation of acetaldehyde was observed in a wide range of SV values. The probability that the latter occurs, however, is almost the same as that of the former because the yields of ethene and acetaldehyde were roughly equal to each other at high SV values, as shown in Figure 1. The produced ethene was converted to propene through dimerization, isomerization, and metathesis (Equations 3 and 4).

\section{Reaction pathways on Sc-modified $\operatorname{In}_{2} \mathrm{O}_{3}$}

\subsection{Overall pathways from ethanol to propene}

The product distributions in the pulse experiments of ethanol were determined at $773 \mathrm{~K}$ as a function of the gas hourly space velocity (GHSV) and are summarized in Figure 2. Unreacted ethanol was detected at 500,000 $\mathrm{h}^{-1}$ but it disappeared at approximately $80,000 \mathrm{~h}^{-1}$. The first observed product was acetaldehyde whose amount was maximized at $300,000 \mathrm{~h}^{-1}$ and decreased at lower SVs. Acetone became the main product at 50,000 $\mathrm{h}^{-1}$, which was accompanied by the co-production of $\mathrm{CO}_{2}$. At $5,000 \mathrm{~h}^{-1}$, the amounts of acetone and $\mathrm{CO}_{2}$ decreased and those of propene, isobutene, and CO increased. All of the results clearly indicated the reaction sequence of ethanol $\rightarrow$ acetaldehyde $\rightarrow$ acetone (and $\mathrm{CO}_{2}$ ) $\rightarrow$ propene and isobutene.

Small amounts of ethene and butenes (except isobutene) were formed in the experiments. No production of propene upon introduction of ethene onto the catalyst was also confirmed in a separated experiment. Both findings indicated little possibility of metathesis reaction of ethene and butenes to give propene. The reaction pathways yielding acetone from ethanol have been suggested as Equations 8 and 9 (totally Equation 13) on oxide catalysts [11, 14, 17]. Propene can be formed from acetone through hydrogenation and subsequent dehydration, as described by Equation 10 [14]. The comprehensive reaction for 
the propene formation is thus Equation 11.

$$
\begin{aligned}
& \mathrm{CH}_{3} \mathrm{CH}_{2} \mathrm{OH} \rightarrow \mathrm{CH}_{3} \mathrm{CHO}+\mathrm{H}_{2} \\
& 2 \mathrm{CH}_{3} \mathrm{CHO}+\mathrm{H}_{2} \mathrm{O} \rightarrow \mathrm{CH}_{3} \mathrm{COCH}_{3}+\mathrm{CO}_{2}+2 \mathrm{H}_{2} \\
& \mathrm{CH}_{3} \mathrm{COCH}_{3}+\mathrm{H}_{2} \rightarrow \mathrm{CH}_{2}=\mathrm{CHCH}_{3}+\mathrm{H}_{2} \mathrm{O} \\
& 2 \mathrm{CH}_{3} \mathrm{CH}_{2} \mathrm{OH} \rightarrow \mathrm{CH}_{2}=\mathrm{CHCH}_{3}+\mathrm{CO}_{2}+3 \mathrm{H}_{2} \\
& 2 \mathrm{CH}_{3} \mathrm{CH}_{2} \mathrm{OH}+\mathrm{H}_{2} \mathrm{O} \rightarrow \mathrm{CH}_{3} \mathrm{COCH}_{3}+\mathrm{CO}_{2}+4 \mathrm{H}_{2} \\
& 3 \mathrm{CH}_{3} \mathrm{CH}_{2} \mathrm{OH}+\mathrm{H}_{2} \mathrm{O} \rightarrow \mathrm{CH}_{2}=\mathrm{C}\left(\mathrm{CH}_{3}\right)_{2}+2 \mathrm{CO}_{2}+6 \mathrm{H}_{2} \\
& \mathrm{CO}_{2}+\mathrm{H}_{2} \rightarrow \mathrm{CO}+\mathrm{H}_{2} \mathrm{O} \\
& \mathrm{A}_{\mathrm{C} 3} / 3+\mathrm{A}_{\mathrm{C} 4} / 2=\mathrm{A}_{\mathrm{COx}}
\end{aligned}
$$

The molar ratios of the total amounts of propene and acetone, $\mathrm{A}_{\mathrm{C} 3}$, with those of carbon dioxide, $\mathrm{A}_{\mathrm{CO} 2}$, were first verified to be 3:1 based on Reactions 11 and 12 . In the calculation, the $\mathrm{A}_{\mathrm{CO} 2}$ values were replaced with the total amounts of carbon dioxide and carbon monoxide, $\mathrm{A}_{\mathrm{COx}}$, because the progress of Reaction 14 was confirmed on the catalyst. In addition, as isobutene formation was revealed to go through acetone as an intermediate, the formation reaction was assumed to be Reaction 13 and the $A_{\mathrm{C} 3}$ values were corrected for quantities of isobutene, $A_{C 4}$. Namely it was verified which Equation 15 was to be established or not in the product distributions. The yields of propene, acetone, isobutene, $\mathrm{CO}_{2}$, and $\mathrm{CO}$ at 773 or $823 \mathrm{~K}$ on the $\mathrm{Sc} / \mathrm{In}_{2} \mathrm{O}_{3}$ catalyst were $43,0.2,21,11$, and 12 , or $62,0.1,15,10$, and 17 , respectively. Using these values, the left-hand side of Equation 15 was 24.9 or 28.2, and the right-hand side was 23 or 28 . The excellent materialization of Equation 15 was observed in the entire product distributions, strongly indicating that the total reactions shown in Reactions 11-14 were correct.

4.2. Formation of acetone from acetaldehyde 
The rough reaction pathways, EtOH $\rightarrow$ acetaldehyde $\rightarrow$ acetone $\rightarrow$ propene, were suggested in the section 4.1. However, the reaction to form acetone from acetaldehyde remained unclear. There are two principal reaction routes for acetaldehyde: the aldol reaction and the Tishchenko reaction. The aldol reaction results in the formation of 3-hydroxybutylaldehyde, $\mathrm{CH}_{3} \mathrm{CH}(\mathrm{OH}) \mathrm{CH}_{2} \mathrm{CHO}$, which can be converted to $\mathrm{CH}_{3} \mathrm{C}(\mathrm{O}) \mathrm{CH}_{2} \mathrm{CHO}$ or $\mathrm{CH}_{2}=\mathrm{CHCH}_{2} \mathrm{CHO}$ by dehydrogenation or dehydration, respectively. The latter would not give acetone, while the former could react with water to yield acetone, $\mathrm{CO}_{2}$, and $\mathrm{H}_{2}[11,12,18]$. We observed, however, no production of $\beta$-hydroxyaldehyde or $\beta$-ketoaldehyde and only a trace amount of crotonaldehyde in the present experiments using GC-MS. These results indicated little possibility of the formation of acetone through the aldol reaction. In contrast, the formation of ethyl acetate was confirmed during the reaction of EtOH on the present catalysts, though the amount varied from 0.1 to $2 \%$, depending on the reaction conditions. This finding might suggest the occurrence of the Tishchenko reaction (Reaction 16) on the catalyst, although the Tishchenko reaction of acetaldehyde is widely accepted to be fairly difficult. This will be discussed again after the reactivity checks of the candidate compounds.

$$
\begin{aligned}
& 2 \mathrm{CH}_{3} \mathrm{CHO} \rightarrow \mathrm{CH}_{3} \mathrm{C}(\mathrm{O}) \mathrm{OCH}_{2} \mathrm{CH}_{3} \\
& \mathrm{CH}_{3} \mathrm{C}(\mathrm{O}) \mathrm{OCH}_{2} \mathrm{CH}_{3}+\mathrm{H}_{2} \mathrm{O} \rightarrow \mathrm{CH}_{3} \mathrm{C}(\mathrm{O}) \mathrm{OH}+\mathrm{CH}_{3} \mathrm{CH}_{2} \mathrm{OH} \\
& \mathrm{CH}_{3} \mathrm{C}(\mathrm{O}) \mathrm{OCH}_{2} \mathrm{CH}_{3} \rightarrow \mathrm{CH}_{3} \mathrm{C}(\mathrm{O}) \mathrm{OH}+\mathrm{CH}_{2}=\mathrm{CH}_{2} \\
& 2 \mathrm{CH}_{3} \mathrm{C}(\mathrm{O}) \mathrm{OH} \rightarrow \mathrm{CH}_{3} \mathrm{C}(\mathrm{O}) \mathrm{CH}_{3}+\mathrm{CO}_{2}+\mathrm{H}_{2} \mathrm{O} \\
& \mathrm{CH}_{3} \mathrm{CHO}+\mathrm{H}_{2} \mathrm{O} \rightarrow \mathrm{CH}_{3} \mathrm{C}(\mathrm{O}) \mathrm{OH}+\mathrm{H}_{2}
\end{aligned}
$$

The reactivity of the potential intermediates was examined on the $\mathrm{Sc} / \mathrm{In}_{2} \mathrm{O}_{3}$ catalyst using a pulse reactor (Table 2). The introduction of ethyl acetate resulted in the formation of acetone, ethene, propene, ethanol, and carbon dioxide. The product distributions suggested 
the progress of Reactions 17 and 18 [12] and a notably fast Reaction 19, where ethyl acetate is converted to acetic acid via the hydrolysis or the decomposition and then to acetone via the ketonization. The significant difference between the product distributions in the reactions of ethanol and ethyl acetate, however, was found in Table 1, which was the amount of produced ethene. The latter reaction gave much larger amount of ethene than the former, suggesting that Reaction 18 would be one of the major reaction paths of ethyl acetate on the catalyst. In addition, the detection of unreacted ethyl acetate in the pulse reaction (Table 1) indicated low reaction rate of ethyl acetate on the catalyst. These two findings implied that ethyl acetate found in the flow-type reaction of $\mathrm{EtOH}$ would not be an intermediate for the acetone formation but be yielded as a by-product via the reverse reaction of Reaction 17, the Fisher esterification.

The direct reaction of aldehydes or alcohols to carboxylic acids in an oxidative atmosphere and their subsequent ketonization [18] has been recognized on various catalysts. This reaction was not observed here because of the absence of oxygen. On the other hand, the direct reaction of an adsorbate $\mathrm{CH}_{3} \mathrm{CH}_{2} \mathrm{O}$ with a surface $\mathrm{OH}$ group was suggested to generate the $\mathrm{CH}_{3} \mathrm{COO}$ species on the oxide surface [19]. This might lead to the formation of acetic acid through one of several possible pathways such as Reaction 20.

Most of the acetic acid was converted to acetone and carbon dioxide, even at very high GHSV, as shown in Table 2. Furthermore, acetaldehyde could indeed afford acetic acid, when the reaction temperature was lowered and water vapor was added in the carrier gas. All of the data obtained by the pulse reactor supported progress of the direct formation of acetic acid from acetaldehyde, and the very fast reaction of acetic acid to form acetone and carbon dioxide. One can also recognize the slow reaction of acetone to propene in this catalytic system from the GHSV values in the table. In conclusion, a novel and complicated 
reaction route from ethanol to propene was found on Sc-loaded $\operatorname{In}_{2} \mathrm{O}_{3}$ catalysts: the reaction proceeds via acetaldehyde, acetic acid, and acetone as the intermediates, with carbon dioxide being generated as a by-product. The findings shed light on the novel and one-step production of propene from renewable bio-ethanol instead of the present thermal or catalytic cracking of naphtha.

\section{Reaction pathways on $\mathrm{Y}_{2} \mathrm{O}_{3}-\mathrm{CeO}_{2}$}

No production of propene upon introduction of ethene onto the $\mathrm{Y}_{2} \mathrm{O}_{3}-\mathrm{CeO}_{2}$ catalyst was confirmed in a separated experiment, indicating little possibility of metathesis reaction of ethene and butenes to give propene. The ratio of the total yield of propene and acetone $\left(\mathrm{A}_{\mathrm{C} 3}\right)$ to those of $\mathrm{CO}_{2}$ and $\mathrm{CO}\left(\mathrm{A}_{\mathrm{COx}}\right)$ were 2.5-3.0, where contribution of the reverse water gas shift reaction (Equation 14) was counted for the $\mathrm{A}_{\mathrm{COx}}$ calculation. The good consistency with the theoretical value 3.0 indicated that acetone was a key intermediate for the propene formation. The differences between the product distributions on $\mathrm{Sc} / \mathrm{In}_{2} \mathrm{O}_{3}$ and $\mathrm{Y}_{2} \mathrm{O}_{3}-\mathrm{CeO}_{2}$ were the amounts of ethene and acetone. Their yields were much larger on $\mathrm{Y}_{2} \mathrm{O}_{3}-\mathrm{CeO}_{2}$ than those on $\mathrm{Sc} / \mathrm{In}_{2} \mathrm{O}_{3}$.

Pulse experiments were carried out on the $\mathrm{Y}_{2} \mathrm{O}_{3} / \mathrm{CeO}_{2}$ using ethyl acetate, acetic acid, and acetone as the substrates. Figure 3 shows the results for ethyl acetate as a function of contact time. In the absence of water, the major product was ethene irrespective of the contact time, although the yields varied from 40 to $60 \%$. The yield of acetone was high ( $\sim 20 \%)$ at the short contact time of $0.11 \mathrm{~s}^{-1}$, and the yields of propene were low (6-20\%) compared to those in the flow reaction system. The co-feed of water with ethanol noticeably increased the yields of both propene and acetone to $10-20 \%$. The results indicated the possibility that ethyl acetate was an intermediate for acetone and ethene formation. 
The results of acetic acid are also shown in the figure. Acetic acid would hardly be generated from ethanol under the non-oxidative condition, but in the presence of water, which is a by-product of ethanol dehydration, acetic acid might be yielded through the direct reaction of an adsorbate $\mathrm{CH}_{3} \mathrm{CH}_{2} \mathrm{O}$ with a surface $\mathrm{OH}$ group. All introduced acetic acid was converted to acetone and $\mathrm{CO}_{2}$ even at the short contact time, wherein the ratios of acetone produced to $\mathrm{CO}_{2}$ were almost 3:1 (carbon basis) except for that at the long contact time. These results indicated the very easy and selective ketonization of acetic acid, agreeing well with the results reported above. The following reaction pathways could be suggested on the basis of the above pulse experiments, although surface intermediates should be detected by for example IR measurements in the future. That is, ethyl acetate was converted to ethene and acetic acid through decomposition (Equation 18), and the subsequent ketonization of produced acetic acid yielded acetone and $\mathrm{CO}_{2}$ (Equation 19) [20].

Finally, the conversion of acetone to propene was confirmed to progress on the catalyst. Differently from the reaction on $\mathrm{Sc} / \mathrm{In}_{2} \mathrm{O}_{3}$, acetone gave only a small amount of propene in the presence of $\mathrm{H}_{2}$ (propene yield was less than 10\%), as shown in Figure 3. In contrast, acetone could be converted to propene in the co-feed of ethanol, suggesting the reduction of acetone by ethanol and the subsequent dehydration of produced 2-propanol to propene. The former reaction is recognized as Meerwein-Ponndorf-Verley (MPV) reduction [21]. The active site could be an acid-base pair consisting of $\mathrm{Ce}^{3+}$ or $\mathrm{Y}^{3+}$ and $\mathrm{O}^{2-}$ ions, which was generated through the formation of oxygen vacancy [22]. Ethanol adsorbed on the acid-base pair site could reduce adsorbed acetone to 2-propanol. The co-fed water might be involved in this reduction, but we have not understood yet the role of water at the molecular level.

Based on the above results and discussion, the following reaction pathways yielding propene from ethanol was suggested on the Y-modified ceria catalyst. Ethanol is 
dehydrogenated to acetaldehyde, and resulting acetaldehyde is dimerized to give ethyl acetate via the Tischenko reaction. Ethyl acetate is then decomposed to give ethene and acetic acid, the latter of which yields acetone and $\mathrm{CO}_{2}$ through the ketonization reaction. Propene was produced by the MPV reduction of acetone by ethanol and the subsequent dehydration reaction. The present mechanism on $\mathrm{Y}_{2} \mathrm{O}_{3}-\mathrm{CeO}_{2}$ is different from those for Ni-MCM-41 [8, 15] and $\mathrm{Sc} / \mathrm{In}_{2} \mathrm{O}_{3}$ catalysts [14]. It should be noted that much amount of ethene was produced at the short contact time in the pulse reaction of ethanol, which would suggest the presence of an alternative route to form ethene through the simple dehydration of ethanol.

\section{Conclusions}

The direct conversion of ethanol to propene was first realized by our recent studies. The yield of propene reached at $60-65 \%$, which were about $80 \%$ of the theoretical maximum yield (75 \%). This would be very significant for a novel utilization of bio-ethanol other than using for the fuel. Three kinds of active catalysts were reported so far; Ni-M41, Sc/ $/ \mathrm{In}_{2} \mathrm{O}_{3}$, and $\mathrm{Y}_{2} \mathrm{O}_{3}-\mathrm{CeO}_{2}$. The reaction pathways were entirely different from each other. The key steps on these three catalysts were metathesis of ethene and butenes, conversion of acetaldehyde to acetic acid and subsequent ketonization, and formation and decomposition of ethylacetate, respectively. It should be noted that there would be many novel catalytic reactions in the field of inter-conversions of C2-C4 (oxygen-containing) hydrocarbons, one of which was found here. The present findings would shed lights on development of the new biomass-refinery.

\section{Acknowledgments}

This work was supported by the New Energy and Industrial Technology Development 
Organization (NEDO, MITI), and the Advanced Low Carbon Technology Research and Development Program (ALCA, JST). Most of the works were carried out by Drs. Fumitaka Hayashi and Masashi Tanaka, Mrs. Shouta Mizuno and Souta Hirakawa, and Ms. Mika Kurosawa. The author also appreciate Dr. Tetsuo Suzuki and Mrs. Osamu Takahashi, Hiroshi Ohashi, and Takahiro Kakinuma of the NEDO research group for helpful discussions.

\section{References}

[1] A. Morschbaker, Polym. Rev. 49 (2009) 79.

[2] For example, G. A. Olah, A. Molnar, "Hydrocarbon Chemistry”, 2nd Ed., John Wiley\&Sons, Inc., New Jersey, 2003, pp.30-84.

[3] C. B. Phillips, R. Datta, Ind. Eng. Chem. Res. 36 (1997) 4466. P. Brandao, A. Philippou, J. Rocha, M. W. Anderson, Catal. Lett. 80 (2002) 99. T. Aguayo, A. G. Gayubo, A. Atutxa, M. Olazar, J. Bilbao, Ind. Eng. Chem. Res. 41 (2002) 4216; J Chem. Technol. Biotechnol. 77 (2002) 211. A. G. Gayubo, A. Alonso, B. Valle, A. T. Aguayo, J. Bilbao, Ind. Eng. Chem. Res. 49 (2010) 10836. A. G. Gayubo, A. Alonso, B. Valle, A. T. Aguayo, M. Olazar, J. Bilbao, Chem. Eng. J. 167 (2011) 262.

[4] I. Takahara, M. Saito, M. Inaba, K. Murata, Catal. Lett. 105 (2005) 249; 113 (2007) 82. M. Inaba, K. Murata, M. Saito, I. Takahara, Green Chem. 9 (2007) 638-646. Z. Song, A. Takahashi, N. Mimura, T. Fujitani, Catal. Lett., 131 (2009) 364. Z. Song, A. Takahashi, I. Nakamura, T. Fujitani, Appl. Catal. A 384 (2010) 201.

[5] D. Arias, A. Colmenares, M. L.Cubeiro, J. Goldwasser, C. M. Lopez , F. J. Machado, V. Sazo, Catal. Lett. 45 (1997) 51. H. Oikawa, Y. Shibata, T. Baba, Appl. Catal. A 312 (2006) 181.

[6] S. Golay, R. Doepper, A. Renken, Chem. Eng. Sci. 5 (1999) $4469 . \quad$ D. N. 
Bakoyannakis, D. Zamboulis, G. A. Stalidis, E. A. Deliyanni, J. Chem. Technol. Biotechnol. 76 (2001) 1159. M. M. Doheim , H. G. El-Shobaky, Coll. Surf. A 204 (2002) 169. T. Zaki, J. Coll. Inter. Sci. 284 (2005) 606. D. Varisli, T. Dogu, G. Dogu, Chem. Eng. Sci. 62 (2007) 5349. D. Varisli, T. Dogu, G. Dogu, Ind. Eng. Chem. Res. 47 (2008) 4071; 48 (2009) 9394. F. Carrasco-Marin, A. Mueden, C. Moreno-Castilla, J. Phys. Chem. B 102 (1998) 9239. S. Kamiguchi, T. Chihara, Catal. Lett. 85 (2003) 97. S. Kamiguchi, S. Nagashima, K. Komori, M. Kodomari, T. Chihara, J. Cluster Sci. 18(2007) 414.

[7] Y. Kamimura, S. Sato, R. Takahashi, T. Sodesawa, T. Akashi, Appl. Catal. A 252 (2003) 2399. O. Nagashima, S.Sato, R. Takahashi, T. Sodesawa, J. Mol. Catal. A 227 (2005) 231. T. Tsuchida, J. Kubo, T. Yoshioka, S. Sakuma, T. Takeguchi, W. Ueda, J. Catal. 259 (2008) 183.

[8] a) M. Iwamoto, Y. Kosugi, J. Phys. Chem. C 111 (2007) 13. K. Ikeda, Y. Kawamura, T. Yamamoto, M. Iwamoto, Catal. Commun. 9 (2008) 106. b) T. Haishi, K. Kasai, M. Iwamoto, Chem. Lett. 40 (2011) 624.

[9] K. Kasai, T. Haishi, M. Iwamoto, Shokubai, 49 (2007) 126. M. Iwamoto, K. Kasai, Jp. Patent P2008-255104A.

[10] S. Sugiyama, Y. Kato, T. Wada, S. Ogawa, K. Nakagawa, K. Sotowa, Top. Catal. 53 (2010) 550.

[11] T. Nakajima, T. Yamaguchi, K. Tanabe, J. Chem. Soc. Chem. Commun., (1987) 394. T. Nakajima, K. Tanabe, T. Yamaguchi, I. Matsuzaki, S. Mishima, Appl. Catal., 52 (1989) 237. R. Sreerama-Murthy, P. Patnaik, P. Sidheswaran, M. Jayamani, J. Catal., 109 (1988) $298 . \quad$ Y. Kamimura, S. Sato, R. Takahashi, T. Sodesawa, T. Akashi, Appl. Catal. A, 252 (2003) 399. Y. Kamimura, S. Sato, R. Takahashi, T. Sodesawa, M. Fukui, Chem. Lett., (2000) 232. T. Tsuchida, J. Kubo, T. Yoshioka, S. Sakuma, T. Takeguchi, W. Ueda, J. Catal., 259 (2008) 183. 
[12] J. I. Di Cosimo, V. K. Diez, M. Xu, E. Iglesia, C.R. Apesteguia, J. Catal., 178 (1998) 499. M. J. L. Gines, E. Iglesia, J. Catal., 176 (1998) 155. A.S. Ndou, N. Plint, N. J. Coville. Appl. Catal. A, 251 (2003) 337. D. J. Elliott, F. Pennella, J. Catal., 119 (1989) 359.

[13] F. Hayashi, M. Iwamoto, ACS Catal., 3 (2013) 14. F. Hayashi, M. Tanaka, M. Iwamoto, J. Catal, in press.

[14] S. Mizuno, M. Kurosawa, M. Tanaka, M. Iwamoto, Chem. Lett., 41 (2012) 892. M. Iwamoto, S. Mizuno, M. Tanaka, Chem. Eur. J., 19 (2013) 7214.

[15] M. Iwamoto, K. Kasai, T. Haishi, ChemSusChem, 4 (2011) 1055.

[16] K. Tsuji, H. Uchida, T. Nakajou, K. Sano, Chem. Chem. Industry 61 (2008) 206.

[17] J. Sun, K. Zhu, F. Gao, C. Wang, J. Liu, C. H. F. Peden, Y. Wang, J. Am. Soc. Chem., 133 (2011) 11096.

[18] G. R. M. Dowson, M. F. Haddow, J. Lee, R. L. Wingad, D. F. Wass, Angew. Chem. Int. Ed., 52 (2013) 9005.

[19] J. Bi, M. Liu, C. Song, X. Wang, X. Guo, Appl. Catal. B, 68 (2011) 107. M. Inaba, K. Murata, M. Saito, I. Takahara, Green Chem., 9 (2007) 638. Z. Song, A. Takahashi, N. Mimura,T. Fujitani, Catal. Lett., 131 (2009) 364.

[20] M. Renz, Eur. J. Org. Chem., (2005) 979.

[21] D. Klomp, T. Mashmeyer, U. Hanefeld, J. A. Peters, Chem. Eur. J., 10 (2004) 2088.

[22] S. Sato, F. Sato, H. Gotoh, Y. Yamada, ACS Catal., 3 (2013) 721. 


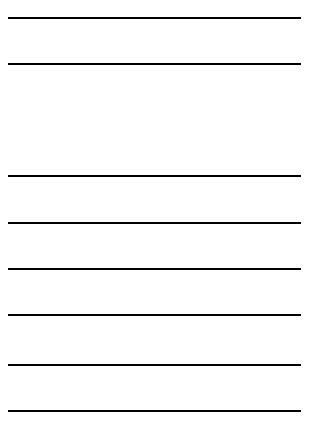




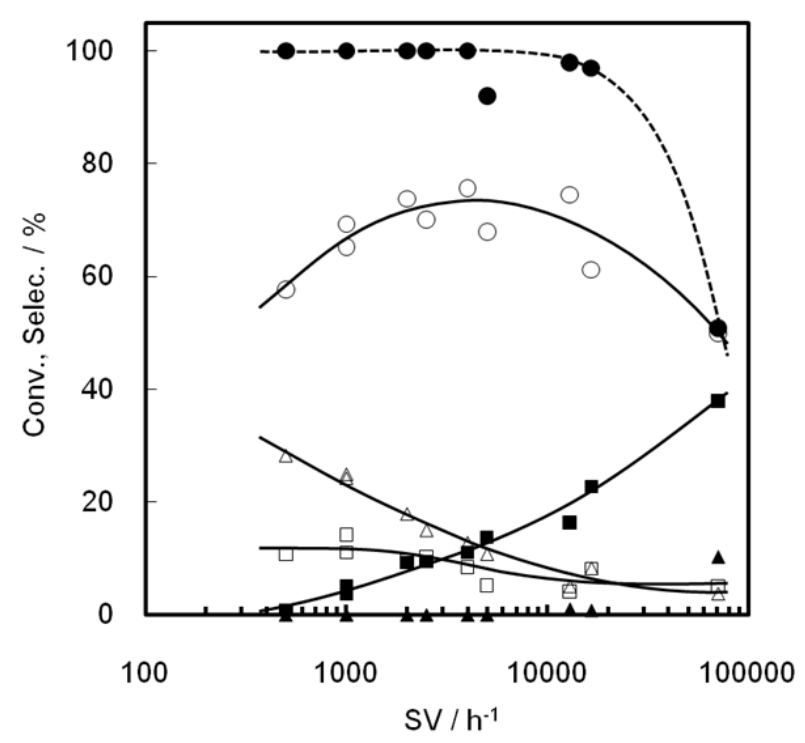

Figure 1. Conversion of ethanol on Ni-M41 ( $\mathrm{Si} / \mathrm{Ni}=23-28)$ as a function of space velocity. Catalyst wt. 0.05-.0.4 g, Flow rate $10-300 \mathrm{ml} / \mathrm{min}, \mathrm{P}_{\mathrm{EtOH}} 5.5 \%\left(\mathrm{~N}_{2}\right.$ balance). Conversion of ethanol (closed circle), selectivity of ethene (open circle), propene (open triangle), butenes (open square), diethylether (closed triangle), and acetaldehyde (closed square).

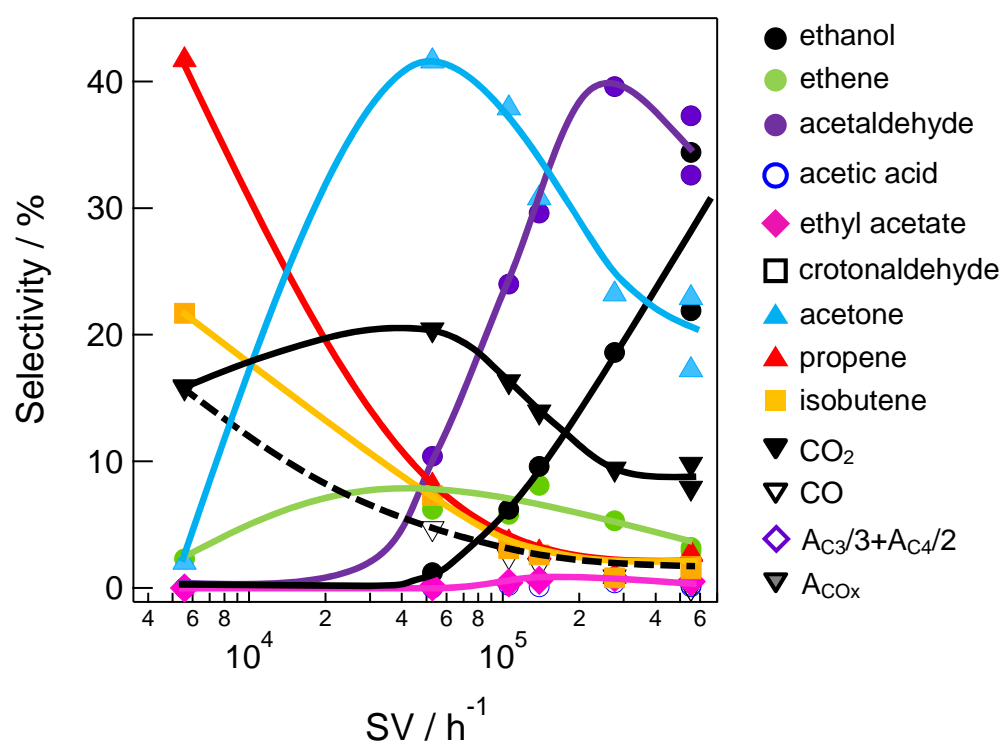

Figure 2. Product distributions upon introduction of an ethanol pulse at $773 \mathrm{~K}$ in a $\mathrm{N}_{2}$ flow. The distributions were measured as a function of GHSV. 


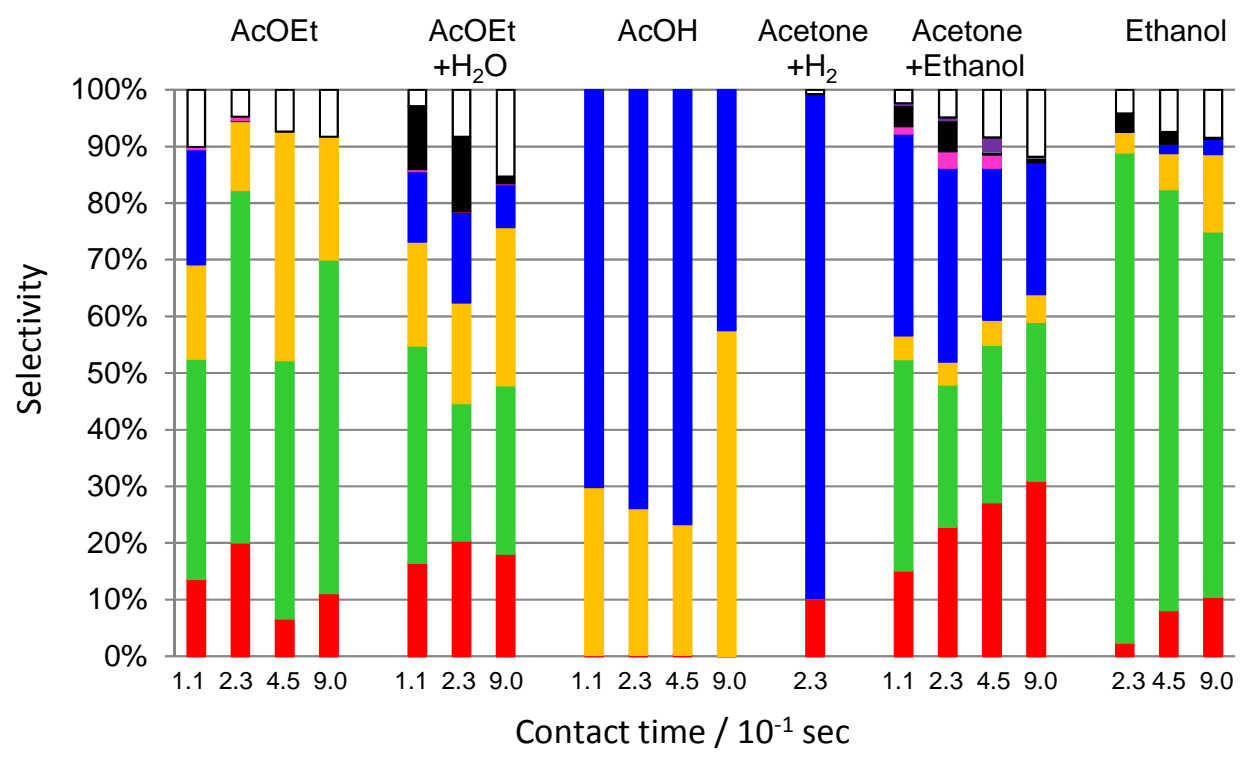

Figure 3. Pulse experiments for the $\mathrm{Y}_{2} \mathrm{O}_{3}-\mathrm{CeO}_{2}$ as a function of contact time. Reactants are ethyl acetate (AcOEt), acetic acid $(\mathrm{AcOH})$, acetone, and ethanol. As needed, water, $\mathrm{H}_{2}$ gas, ethanol was fed with the reactants. Reaction conditions: pulse size, $2.0 \mu \mathrm{l}$, catalyst weight, $0.1 \mathrm{~g}$; total flow rate, $10-80 \mathrm{ml} \mathrm{min}^{-1}$; reaction temperature, $703 \mathrm{~K}$. Red, propene; green, ethene; orange, $\mathrm{CO}_{2}$; blue, acetone; pink, AcOH; black, ethanol; gray, AcOEt; purple, acetaldehyde; white, others. 